\title{
XÂY DỤ̉NG CHƯƠNG TRÌNH ĐÀO TẠO THEO HƯỚNG TIẾP CẬN CDIO VÀ CHUẢN AUN-QA: MỤC TIÊU CHIẾN LỰ̛̣C CỦA TRƯờnG ĐẠI HỌC THỦ DẦU MỘT ĐẾN NĂM 2030
}

\author{
Nguyễn Hoàng Huế $\hat{e}^{(*)}$ \\ ${ }^{(*)}$ Tiến sĩ. Truòng Đại học Thủ Dầu Một.Email: $\underline{\text { huenh @tdmu.edu.vn }}$
}

DOI: $\underline{10.37550 / t d m u . C F R / 2021.01 .111 ~}$

\section{Tóm tắt}

Qua hơn 10 năm hình thành và phát triển, Trường Đại học Thủ Dầu Một đã đạt được nhũng kết quả khá toàn diện, quy mô phát triển nhanh và đúng huoóng. Trong quá trình xây dựng và phát triển, Trương Đại học Thủ Dầu Một luôn coi việc nâng cao chất luợng giáo dục và đào tạo là nhiệm vu sống còn và cũng là trọng trách của mình trong chiến luợc phát triển kinh tế - xã hội của đất nuớc. Việc xây dựng và phát triển chuơng trình đào tạo (CTĐT) theo huớng tiếp cận CDIO và chuẩn AUN-QA thể hiện quyết tâm của Truờng Đại hoc Thủ Dầu Một trong việc nâng cao chất luợng giảng dạy, xây dựng thuơng hiệu uy tín, cạnh tranh, nhằm tạo ra một thế hệ sinh viên bản lĩnh, tụ tin và đáp ứng được nhu cầu của xã hội. Đây là bước khởi đầu quan trọng trong lộ trình dài phía trước, đòi hỏi sụ đồng tâm hiệp lục của toàn thể đội ngũ cán bộ giảng viên, nhân viên và sinh viên Nhà trường để đạt được muc tiêu chiến lược trở thành trường đại học thông minh có uy tín trong nước và quốc tế, vào tốp 200 đại học tốt nhất châu Á.

Tù̀ khóa: chuơng trình đào tạo, chiến lược, $C D I O, A U N-Q A$.

\section{1. Đặt vấn đề}

Từ lý luận đến thực tiễn cho thấy, việc xây dựng và phát triển chương trình đào tạo theo hướng tiếp cận $\mathrm{CDIO}$ và chuẩn $\mathrm{AUN}-\mathrm{QA}$ sẽ góp một phần vào việc giải bài toán "chất lượng giáo dục đại học" hiện nay. Thực tế ở các đại học thuộc các quốc gia trong khu vực đã chứng minh việc áp dụng phương pháp hay cách tiếp cận CDIO và chuẩn AUN-QA sẽ gắn với nhu cầu của người tuyển dụng, từ đó giúp thu hẹp khoảng cách giữa đào tạo của nhà trường và yêu cầu của nhà sử dụng nguồn nhân lực; giúp người học phát triển toàn diện, nhanh chóng thích ứng với môi trường làm việc luôn thay đổi và thậm chí là đi đầu trong việc thay đổi đó.

Trong bối cảnh Việt Nam đang hội nhập mạnh mẽ với khu vực và quốc tế, việc xây dựng chương trình đào tạo theo hướng tiếp cận CDIO và chuẩn AUN-QA có một ý nghĩa quan trọng, đáp ứng yêu cầu nguồn nhân lực trong quá trình hội nhập và phát triển. 
Khi Việt Nam càng hội nhập sâu rộng vào thế giới thì năng lực con người càng được đo lường một cách chính xác, do đó, sinh viên, lực lượng lao động trẻ tương lai, phải nỗ lực học tập, rèn luyện nhiều hơn nữa, bên cạnh kiến thức mà mình có được từ Nhà trường, các bạn phải chủ động trang bị cho mình vốn ngoại ngữ và kỹ năng cần thiết để hòa nhập vào Cộng đồng ASEAN nói riêng và thế giới nói chung.

\section{Nội dung}

\subsection{Khái quát về CDIO và $A U N$}

CDIO là một sáng kiến mới cho giáo dục, là một hệ thống các phương pháp và hình thức tích lũy tri thức, kỹ năng trong việc đào tạo sinh viên để đáp ứng yêu cầu của doanh nghiệp và xã hội. CDIO (Conceive - hình thành ý tưởng; Design - thiết kế ý tưởng; Implement - thực hiện; Operate - vận hành) là một giải pháp nâng cao chất lượng đào tạo đáp ứng yêu cầu xã hội trên cơ sở xác định chuẩn đầu ra $(\mathrm{CĐR})$ để thiết kế chương trình và phương pháp đào tạo theo một quy trình khoa học. Xây dựng chương trình đào tạo theo cách tiếp cận $\mathrm{CDIO}$ nhằm đào tạo sinh viên phát triển toàn diện cả về kiến thức, kỹ năng, thái độ, năng lực thực tiễn (năng lực C-D-I-O) và có ý thức trách nhiệm với xã hội [1].

Theo cách tiếp cận $\mathrm{CDIO}$, khi xây dựng và nâng cấp các chương trình đào tạo phải

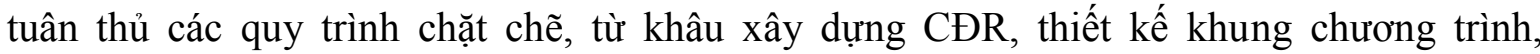
chuyển tải khung chương trình vào thực tiễn và đánh giá kết quả học tập của sinh viên cũng như toàn bộ chương trình. Việc xây dựng chuẩn đầu ra theo hướng tiếp cận CDIO cho các chương trình đào tạo và một hệ thống các phương pháp và hình thức tích lũy tri thức, kỹ năng trong việc đào tạo sinh viên để đáp ứng yêu cầu của doanh nghiệp và xã hội. Tiếp cận theo đề xướng CDIO là cách tiếp cận phát triển, phù hợp xu thế, khuynh hướng phát triển của thế giới, gắn phát triển chương trình với chuyển tải và đánh giá hiệu quả giáo dục đại học nhưng mỗi cơ sở giáo dục đều có bối cảnh riêng, không thể áp dụng một cách cứng nhắc đề xướng $\mathrm{CDIO}$. Khi tiếp cận $\mathrm{CDIO}$ và ứng dụng vào đào tạo, xây dựng và nâng cấp chương trình đào tạo phải tuân thủ các quy trình chặt chẽ, từ khâu xây dựng $\mathrm{CĐR}$, thiết kế khung chương trình, chuyển tải nội dung chương trình vào thực tiễn và đánh giá kết quả nguồn nhân lực đầu ra cũng như toàn bộ chương trình.

AUN (ASEAN University Network) là tổ chức phi chính phủ, phi lợi nhuận được thành lập năm 1995 với mục đích thúc đẩy sự hợp tác và nâng cao chất lượng đào tạo, nghiên cứu, trao đổi giảng viên và sinh viên giữa các trường trong $\mathrm{ASEAN}$.

Khung đảm bảo chất lượng AUN-QA (ASEAN University Network - Quality Assurance) được xây dựng nhằm giúp cải tiến chất lượng giáo dục trong khu vực, hỗ trợ sự lưu động của người học, người lao động và chuyên gia giữa các quốc gia trong khu vực và với quốc tế. Bộ khung được nghiên cứu, xây dựng và cải tiến để đảm bảo các quốc gia có thể áp dụng trong những bối cảnh chính trị, văn hóa và pháp luật khác nhau mà không ảnh hưởng đến những giá trị và truyền thống cốt lõi của từng quốc gia [4; tr7].

AUN-QA là mạng lưới chuyên trách về ĐBCL giáo dục đại học của $A U N$, được thành lập với nhiệm vụ thúc đẩy hoạt động ĐBCL tại các cơ sở giáo dục đại học, nâng cao 
chất lượng giáo dục đại học và hợp tác với các tổ chức trong khu vực và quốc tế vì lợi ích chung của cộng đồng ASEAN.

Hoạt động đánh giá chất lượng cấp chương trình đào tạo (CTĐT) được AUN-QA triển khai từ năm 2007. Đến nay hơn 160 chương trình đã được đánh giá bởi AUN-QA góp phần đem lại nhiều lợi ích cho các trường đại học là thành viên chính thức và thành viên liên kết của mạng lưới.

Nhằm đáp ứng các thách thức trong cộng đồng chung ASEAN, mạng lưới AUN-QA tiên phong thúc đẩy việc hình thành một khung đảm bảo chất lượng (ĐBCL) giáo dục đại học hài hòa cả trong và ngoài $\mathrm{ASEAN}$. Để đạt được mục tiêu này, AUN-QA cần đảm bảo rằng khung $\mathrm{ĐBCL}$ và các tài liệu hướng dẫn được xây dựng phù hợp và mang tính cập nhật. Đến nay, đã có phiên bản 4.0 của tài liệu hướng dẫn đánh giá chất lượng cấp chương trình là thành quả của quá trình rà soát, điều chỉnh của nhóm chuyên gia AUN-QA.

Bộ tiêu chuẩn kiểm định chất lượng của Mạng lưới Đại học Đông Nam Á - AUN yêu cầu các Trường Đại học cần phải lấy người học làm trung tâm; xác định chuẩn đầu ra rõ ràng cho từng chương trình cụ thể, sinh viên sau khi ra trường phải nắm được những kỹ năng và kiến thức cần thiết; sự thành công của chương trình đào tạo phải được đánh giá bằng những phản hồi của các bên liên quan, kết quả cuối cùng sẽ được Hội đồng quốc tế kiểm định. Việc kiểm định theo chuẩn AUN là sự khẳng định về chất lượng sản phẩm đầu ra của chương trình đào tạo trên hệ tham chiếu mang tính quốc tế, tạo điều kiện cho sinh viên tiếp cận công việc một cách dễ dàng, giúp người sử dụng lao động có một cơ sở tin cậy khi tìm kiếm nguồn nhân lực cho mình.

\subsection{Xây dụng và phát triển chuơng trình đào tạo theo hướng tiếp cận CDIO và chuẩn AUN-QA}

Xây dựng và phát triển chương trình đào tạo theo hướng tiếp cận $\mathrm{CDIO}$ và chuẩn AUN-QA nhằm nâng cao chất lượng đào tạo đáp ứng yêu cầu xã hội trên cơ sở xác định chuẩn đầu ra để thiết kế nội dung chương trình và kế hoạch đào tạo. Tiếp cận $\mathrm{CDIO}$ và chuẩn AUN-QA trước tiên được hiểu là về phương pháp tổng thể, tức là xuất phát từ năng lực cốt lõi của ngành để từ đó xây dựng và tổ chức chương trình đào tạo. Thứ 2 , cung cấp các hướng dẫn cụ thể về qui trình và các hướng dẫn cụ thể xây dựng, tổ chức và đánh giá chương trình đào tạo và qui trình này mang tính chung hóa cao có thể áp dụng cho nhiều ngành đào tạo khác nhau.

Trên cơ sở xác định chuẩn đầu ra của CTĐT, đề xuất một phương pháp, làm cơ sở lí thuyết cho việc vận dụng linh hoạt các luận điểm cơ bản của $\mathrm{CDIO}$ và chuẩn $\mathrm{AUN}-\mathrm{Q} A$ vào thực tiễn đào tạo các ngành nghề đảm bảo nâng cao được chất lượng dạy học đáp ứng nhu cầu xã hội. Đề xướng CDIO và chuẩn AUN-QA là công cụ hướng tới việc giúp sinh viên có được kiến thức, kỹ năng cứng và mềm cần thiết khi ra trường, đáp ứng yêu cầu, đòi hỏi của xã hội cũng như bắt nhịp được với những thay đổi vốn rất nhanh của thực tiễn xã hội. Trường Đại học Thủ Dầu Một lựa chọn mô hình phát triển chất lượng đào tạo theo đề xướng CDIO và chuẩn AUN-QA nhằm thực hiện mục tiêu: Giải quyết việc làm cho sinh viên tốt nghiệp; Đào tạo đáp ứng nhu cầu xã hội; CTĐT phải được tích hợp cả kiến thức, kỹ năng và thái độ; Nâng cao năng lực giảng viên về chuyên môn, nghiệp vụ và phương pháp giảng dạy; Nâng cao chất lượng đào tạo đáp ứng chuẩn kiểm định của khu vực và trên thế giới. 
Mô hình đào tạo theo hướng tiếp cận $\mathrm{CDIO}$ và chuẩn $\mathrm{AUN}-\mathrm{QA}$ tập trung vào chất lượng của các hoạt động đào tạo ở những khía cạnh: 1) Chất lượng đầu vào;2) Chất lượng quá trình đào tạo; 3) Chất lượng đầu ra.

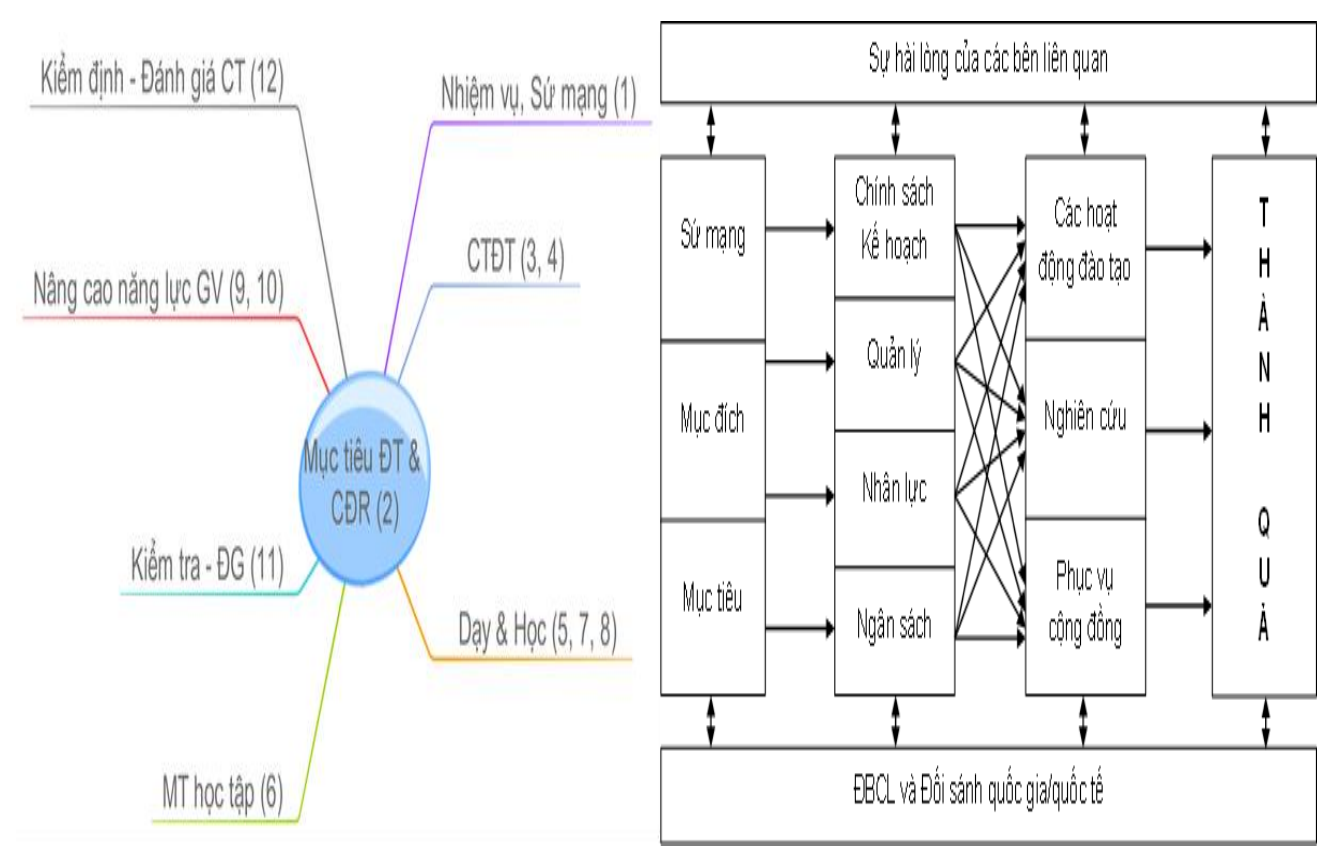

Bộ 12 tiêu chuẩn CDIO và 11 tiêu chuẩn $A U N-Q A$

Theo cách tiếp cận CDIO và chuẩn $A U N-Q A$, khi xây dựng và nâng cấp các chương trình đào tạo phải tuân thủ các quy trình chặt chẽ, từ khâu xây dựng $\mathrm{CĐR}$, thiết kế khung chương trình, chuyển tải khung chương trình vào thực tiễn và đánh giá kết quả học tập của sinh viên cũng như toàn bộ Chương trình.

Có thể nói cốt lõi của xây dựng và phát triển chương trình đào tạo theo cách tiếp cận CDIO và chuẩn $A U N-Q A$ chính là 3 sản phẩm: chuẩn đầu ra, khung chương trình và bộ tiêu chuẩn. Tức là, đào tạo sẽ gắn với nhu cầu của người tuyển dụng, từ đó giúp thu hẹp khoảng cách giữa đào tạo của nhà trường và yêu cầu của nhà sử dụng nguồn nhân lực; giúp người học phát triển toàn diện, nhanh chóng thích ứng với môi trường làm việc luôn thay đổi và thậm chí là đi đầu trong việc thay đổi đó. Sinh viên sau khi hoàn thành chương trình học sẽ được trang bị nhiều kiến thức và kỹ năng đáp ứng yêu cầu thời kỳ hội nhập và phát triển.

\subsection{Mục tiêu chiến lực của Truờng Đại học Thủ Dầu Một đến năm 2030}

Trong quá trình xây dựng và phát triển, Trường Đại học Thủ Dầu Một đã khẳng định sứ mệnh của Nhà trường:

- Sứ mệnh: Là trung tâm văn hóa, giáo dục và khoa học, công nghệ. Cung cấp nguồn nhân lực, sản phẩm khoa học và công nghệ có chất lượng phục vụ phát triển kinh tế xã hội và hội nhập quốc tế tỉnh Bình Dương, miền Đông Nam Bộ và cả nước.

- Tầm nhìn: Trở thành trường đại học thông minh có uy tín trong nước và quốc tế, vào tốp 200 đại học tốt nhất châu Á. 
- Giá trị cốt lõi:

Khát vọng (Aspiration): có ý thức phấn đấu vươn lên đỉnh cao trí thức, ước vọng tới những điều tốt đẹp và quyết tâm thực hiện một cách mạnh mẽ nhất.

Trách nhiệm (Responsibility): có thái độ tích cực và tinh thần trách nhiệm với chính mình, với gia đình, xã hội, Tổ quốc, nhân loại; có đủ năng lực và kỹ năng để chịu trách nhiệm.

Sáng tạo (Creativity): có tư duy đổi mới, có đủ năng lực và trình độ chuyên môn để tạo ra giá trị mới đáp ứng yêu cầu và phục vụ cho sự phát triển của xã hội.

- Triết lý giáo dục: Học tập trải nghiệm - Nghiên cứu khoa học ứng dụng - Phục vụ cộng đồng.

Sinh viên trở thành người phát triển toàn diện về năng lực và tố chất thông qua quá trình học tập trải nghiệm, kết hợp với $\mathrm{NCKH}$ nhằm phục vụ cộng đồng.

Theo đuổi triết lý giáo dục "Học tập trải nghiệm - Nghiên cứu khoa học ứng dụng Phục vụ cộng đồng", nhà trường tạo ra môi trường văn hoá học tập ứng dụng và nuôi dưỡng khát vọng phục vụ cộng đồng của sinh viên. Nhà trường tin rằng sinh viên sẽ trở thành người hữu ích của xã hội, có ý thức phục vụ cộng đồng và thể hiện trách nhiệm của người trí thức thông qua việc học tập trải nghiệm để hình thành năng lực nghề nghiệp, khả năng $\mathrm{NCKH}$, lòng đam mê sáng tạo và sự tôn trọng đạo đức nghề nghiệp (theo nghị quyết số 05/NQ-HĐTr ngày 22/06/2018).

\section{Kết luận}

Trong quá trình xây dựng và phát triển, Trường Đại học Thủ Dầu Một luôn coi việc nâng cao chất lượng giáo dục và đào tạo là nhiệm vụ sống còn và cũng là trọng trách của mình trong chiến lược phát triển kinh tế - xã hội của đất nước.

Việc lựa chọn xây dựng chương trình đào tạo theo cách tiếp cận CDIO và chuẩn AUNQA của Trường Đại học Thủ Dầu Một không chỉ đem lại lợi ích cho nhà trường, sinh viên mà cả người sử dụng lao động. Đối với nhà trường, thông qua hoạt động tự đánh giá và đánh giá ngoài, những điểm mạnh và điểm tồn tại của chương trình đào tạo đã được chỉ ra, và nhà trường phải có kế hoạch hành động cụ thể để cải tiến khắc phục những tồn tại này. Đây là cái được lớn nhất từ phía nhà trường. Đồng thời, gián tiếp hưởng lợi là sinh viên và giảng viên vì môi trường dạy và học được cải thiện, nâng cấp và đảm bảo chất lượng. Nhà trường xác định được vị thế của chương trình đào tạo trong khu vực và làm cơ sở để xây dựng lộ trình phát triển cho chương trình đào tạo theo hướng vươn tới các chuẩn mực quốc tế.

Trong khi đó, sinh viên là đối tượng được hưởng lợi rất lớn từ hoạt động xây dựng CTĐT và đánh giá này, bởi được học tập trong một môi trường được cải tiến liên tục và đảm bảo chất lượng; Kết quả kiểm định $\mathrm{AUN}$ như một sự khẳng định chương trình đào tạo với xã hội về chất lượng sản phẩm đầu ra của chương trình, vì thế chắc chắn sinh viên tiếp cận việc làm phù hợp dễ dàng hơn; Trong tương lai gần, tham gia kiểm định chương trình đào tạo theo chuẩn AUN-QA còn tạo điều kiện cho sinh viên được chuyển đổi tín chỉ học tập giữa các chương trình đào tạo của các trường đại học thành viên AUN; tạo lợi thế cho 
hoạt động trao đổi sinh viên, giảng viên giữa các trường đại học. Và cuối cùng, người sử dụng lao động có một cơ sở tin cậy để tìm kiếm nguồn nhân lực đảm bảo chất lượng, từ một chương trình đào tạo có những tham chiếu chất lượng mang tính quốc tế hóa.

Chuẩn kiểm định chất lượng AUN đang là cái đích mà nhiều trường đại học tại Việt Nam và trong khu vực Đông Nam Á hướng tới. Mục tiêu của các trường đại học không chỉ là thu hút học viên mà còn khẳng định chất lượng đào tạo và dần tiến tới là việc xây dựng văn hóa chất lượng của một trường đại học.

Bởi lẽ, mục đích của việc lựa chọn xây dựng chương trình đào tạo theo cách tiếp cận $\mathrm{CDIO}$ và chuẩn $\mathrm{AUN}-\mathrm{QA}$ là:

- Bảo đảm và nâng cao chất lượng chương trình đào tạo.

- Xác nhận mức độ chương trình đào tạo đáp ứng mục tiêu đề ra trong từng giai đoạn nhất định.

- Làm căn cứ giải trình với các cơ quan quản lý nhà nước có thẩm quyền và xã hội về thực trạng chất lượng của chương trình đào tạo.

- Làm cơ sở cho người học lựa chọn chương trình đào tạo và nhà tuyển dụng lao động tuyển chọn nhân lực.

Nếu như việc đảm bảo và cải tiến chất lượng là quá trình được thực hiện thường xuyên, liên tục bên trong nhà trường thì trách nhiệm giải trình về chất lượng với các bên liên quan cần có sự chứng thực của một bên thứ ba - đó là các tổ chức đánh giá/kiểm định chất lượng có uy tín của quốc gia, khu vực, hay quốc tế. Do đó, Trường Đại học Thủ Dầu Một đã xác định phải coi việc nâng cao chất lượng giáo dục và đào tạo là nhiệm vụ sống còn và cũng là trọng trách của mình trong chiến lược phát triển kinh tế - xã hội của đất nước.

\section{Tài liệu tham khảo}

[1] Ban Thư ký CDIO (2015), Đại học Thủ Dầu Một quyết tâm triển khai xây dưng chương trình đào tạo mói theo mô hình CDIO, http://www.thudaumot.edu.vn/CDIO/Tin-tuc-CDIO-20/DAIHOC-THU-DAU-MOT-QUYET-TAM-TRIEN-KHAI-XAY-DUNG-CHUONG-TRINH-DAOTAO-MOI-THEO-MO-HINH-CDIO-905, ngày truy cập 18/11/2020.

[2] Bộ Giáo dục và Đào tạo (2016), Thông tu Số: 04/2016/TT-BGDĐT Ban hành Quy định về tiêu chuẩn đánh giá chất luợng chương trình đào tạo các trình độ của giáo dục đại học, Hà Nội, ngày 14 tháng 3 năm 2016.

[3] Cục quản lý chất lượng (2018), Công văn Số: 769/QLCL-KĐCLGD V/v sư dụng tài liệu huớng dẫn đánh giá theo tiêu chuẩn đánh giá chất luợng CTÐT các trình độ của GDĐH, Hà Nội, ngày 20 tháng 4 năm 2018 .

[4] Đại học quốc gia TP.HCM (2016), Tài liệu huoóng dẫn Tài liệu huớng dẫn đánh giá chất luoọng cấp chuoong trình theo tiêu chuẩn AUN-QA (phiên bản 3.0), NXB Đại học Quốc gia TPHCM.

[5] Trường Đại học Thủ Dầu Một (2018), Kế hoạch chiến luợc đảm bảo chất luợng của Truờng Đại học Thủ Dầu Một (giai đoạn 2018-2020, tầm nhìn 2030), ngày 27/09/2018. 